\title{
ROLE OF NATURAL KILLER T LYMPHOCYTES DURING HELMINTHIC INFECTION
}

\author{
FAVEEUW C.*, MALLEVAEY T.*,** \& TROTTEIN F.*
}

\section{Summary:}

Natural killer (NK)T cells are innate lymphocytes that release important amount of immunoregulatory cytokines (IFN- $\gamma$ and/or IL-4) shortly after T cell receptor engagement by (glycollipid antigens presented by the CDId molecules. Through this property, NKT cells play pivotal role in many physiopathologic situations. Here, we review the current knowledge of the functions and mechanisms of activation of NKT cells during infection, with a particular emphasis on helminthic infections. Recent findings suggest that, although dispensable for host resistance, NKT cells play part in the development of the acquired immune response and in the control of the pathology during murine schistosomiasis.

KEY WORDS : helminths, lipid antigens, CDI molecules, Natural Killer T cells, Th1/Th2 responses.

$\tau$ $\mathrm{t}$ is now well established that the $\mathrm{T}$ cell repertoire includes cells recognizing peptide antigens (Ags) presented by the highly polymorphic class I and class II major histocompatibility complex (MHC) molecules as well as cells reactive to (glyco)lipid Ags presented by a family of conserved MHC class I-like cell surface glycoproteins known as the CD1 molecules. These molecules are classified in two groups (Porcelli \& Moldin, 1999): group one comprising CD1a, CD1b and $\mathrm{CD} 1 \mathrm{c}$, is present only in humans and group 2, the CD1d molecules, is present in most species examined so far. Although diverse endogenous as well as microbial (mainly mycobacterial) lipid Ags have been described for the group 1 of CD1 molecules, the nature of self or foreign lipid Ags that naturally bind to CD1d remains poorly defined (Willcox et al., 2007). Diverse populations of $\mathrm{T}$ cells recognize CD1-presented lipids but in this review, we will focus on CD1d-restricted Natural Killer T (NKT) cells.

\footnotetext{
*Institut National de la Recherche Médicale, U547, Institut Pasteur de Lille, 1, rue du Professeur Calmette, Lille, 59019, France.

** Present address. University of Colorado Health Sciences Center and National Jewish Medical and Research Center, Denver, Colorado, 80206, USA.

Correspondence: Unité Inserm U547, Institut Pasteur de Lille, 1, rue du Professeur Calmette, 59019 Lille Cedex, France.

Tel.: 33 (0)32087 7885 - Fax: 33 (0)3 20877888.

E-mail: francois.trottein@pasteur-lille.fr
}

\section{NKT CELL DEFINITION AND CLASSIFICATION}

$\mathrm{N}$ KT cells represent a heterogeneous population of innate/memory unconventional $\mathrm{T}$ lymphocytes that co-express both T and NK cell markers, including the $\mathrm{T}$ cell receptor (TCR) $\alpha \beta$ and the C-type lectin NK1.1 (or CD161 in humans), respectively (Godfrey et al., 2004a). The major subset of NKT cells expresses a single $\alpha$-chain (V $\alpha 14-J \alpha 18$ in mice and Vo24-J $\alpha 18$ in humans) associated with a limited number of $\beta$-chains (V $\beta 8.2, \mathrm{~V} \beta 7$ or V $\beta 2$ in mice and V $\beta 11$ in humans). This cell population, referred as invariant NKT cells (iNKT cells), is found in various peripheral organs including spleen, lymph nodes and liver. Invariant NKT cells recognize a limited number of synthetic or natural lipids (glycolipids and phospholipids) presented by the CD1d molecules expressed by Ag presenting cells (APCs), including dendritic cells (DCs). So far, the best characterized iNKT cell agonist in mice and humans is $\alpha$-galactosylceramide ( $\alpha$-GalCer), a $\alpha$-linked glycosphingolipid (GSL) originally isolated from a marine sponge (Bendelac et al., 2007). Along with $\alpha-$ GalCer, growing evidence suggest that some microorganisms, including Mycobacteria, $\alpha$-Proteobacteria (Sphingomonas, Borrelia) and protozoan parasites (Leishmania, Plasmodium) also produce CD1d-restricted ligands capable of activating a proportion of iNKT cells (Bendelac et al., 2007). In parallel, iNKT cells, which are intrinsically autoreactive, can respond to self Ags. Among them is isoglobotrihexosylceramide (iGb3), a lysosomal $\beta$-inked GSL (Bendelac et al., 2007), although the physiological relevance of this finding has been called into question recently. Along with iNKT cells, other CD1d-restricted NKT cell subpopulations with more diverse TCRs (termed non-iNKT cells) have been described in mice and humans but these cells have been less well studied, mainly because they lack known specific markers (Godfrey et al., 2004a).

\section{NKT CELL FUNCTIONS}

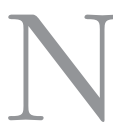

KT cells are part of the innate immune system and play a critical role in the control of the adaptive immune response. Most of our under- 
standing on the role of iNKT cells in the modulation of immune responses derived from the use of the surrogate ligand $\alpha$-GalCer. In vivo and in vitro stimulation of iNKT cells by $\alpha$-GalCer promptly induces the production of high amounts of type 1 (IFN- $\gamma$ ), type 2 (IL-4, IL-5, IL-13), type 17 as well as immunosuppressive/anti-inflammatory (IL-10) cytokines (Godfrey et al., 2004b; Michel et al., 2007). This cytokine burst in turn amplifies or regulates innate/adaptive immune responses by influencing the function of DCs, B and NK cells as well as conventional $\mathrm{CD}^{+}$and $\mathrm{CD}^{+} \mathrm{T}^{+} \mathrm{ym}-$ phocytes (Kronenberg, 2005). One important and intriguing property of iNKT cells is their functional flexibility. Indeed, except for extreme conditions (like stimulation with strong agonists such as $\alpha$-GalCer), iNKT cells may produce only a set of cytokines in physiopathologic conditions. Thus, according to the nature and concentration of lipid Ags, to the microenvironment (cytokines,...) as well as to the type of APCs, iNKT cells can differentially orientate the ensuing immune response, through selective cytokine release. Due to this property, iNKT cells have been implicated in many pathological situations in vivo, including autoimmune diseases, inflammation, resistance to tumors and antimicrobial host response (Godfrey et al., 2004b; Tupin et al., 2007). In these settings, their effects are either protective (tumor resistance) or deleterious (asthma, atherosclerosis), although their exact mechanisms of action remain largely unclear. Two functionally distinct populations of iNKT cells, based on $\mathrm{CD} 4$ expression, have been reported; the CD4subset being more efficient at promoting Th1-mediated immune responses relative to their $\mathrm{CD}^{+}$counterparts (Crowe et al., 2005). Important progress has also been made concerning the functions of non-iNKT cells. A role for non-iNKT cells has been documented in some inflammatory/autoimmune diseases (hepatitis, experimental autoimmune encephalomyelitis, ulcerative colitis), infectious diseases (Trypanosoma cruzi) and in tumour immunity (Ambrosino et al., 2007; Duthie et al., 2005; Fuss et al., 2004; Halder et al., 2007). Interestingly, iNKT and non-iNKT cells exert opposite and counteractive roles in the regulation of tumour immunosurveillance (Ambrosino et al., 2007).

\section{MECHANISMS OF (i)NKT CELL ACTIVATION DURING INFECTIOUS DISEASES}

T nvariant NKT cells generally contribute to antimicrobial host response via downstream activation of some effectors cells, such as NK cells and $\mathrm{CD}^{+} \mathrm{T}$ lymphocytes (Tupin et al., 2007). During infection, it is likely that DCs exposed to microbial products play key role in iNKT cell activation. The proposed scenario is that microbes activate iNKT cells by either providing CD1d-restricted lipids and/or by producing conserved molecular patterns able to trigger an appropriate maturation program in DCs. Indeed, some pathogens can produce lipids, such as $\alpha$-linked GSLs or glycosyldiacylglycerol, able to direcly activate mouse iNKT cells (IFN- $\gamma$ and IL- 4 production) through their TCR (Tupin et al., 2007). On the other hand, for the vast majority of pathogens, it appears that engagement of some innate sensors, including Toll-like receptors (TLRs), expressed by DCs is important to initiate iNKT cell response. For instance, lipopolysaccharide from Gram negative bacteria recruits TLR4 to induce the production of inflammatory cytokines (IL-12, IL-18), and possibly the generation of self CD1d-restricted ligands (such as iGb3) by DCs, to trigger IFN- $\gamma$ synthesis by iNKT cells (Brigl et al., 2003; Mattner et al., 2005; Nagarajan \& Kronenberg, 2007)). In parallel, our group has recently shown that TLR7- and TLR9-stimulated mouse DCs can stimulate the production of IFN- $\gamma$ by iNKT cells (Paget et al., 2007). In this process, type I interferon (but not IL-12) and CD1d-restricted $\beta$-linked GSLs play part in iNKT cell activation. Thus, in response to pathogens, iNKT cells can initiate immune responses through the release of cytokines, which is triggered by TCR ligation by microbial or self lipids, cytokines produced from APCs or both.

\section{NKT CELLS IN HELMINTH PARASITIC INFECTIONS}

lbeit widely studied during viral, bacterial and
protozoan parasite infections, the role of NKT
cells during metazoan parasite infections remain largely unexplored. Worldwide, more than two billion people are infected by helminth parasites. Chronic infections with helminths, including nematodes and trematodes, are associated with a dominant Th2-type immune response, characterized by an increased number of IL4 and IL-5-producing T lymphocytes, elevated eosinophilia and IgE production. Because NKT cells can release IL-4 upon activation, we and other hypothesized that these cells might be important players in the initial steps leading to Th2 responses during helminthiasis.

\section{NEMATODE INFECTIONS}

The role of NKT cells during nematode infections remains ill-defined. A pioneer work from Balmer and co-workers reported an expansion of NKT cells (on the basis of CD3 and NK1.1 markers) in the spleen and draining lymph nodes of mice, as early as 24 hrs following infection with Brugia pahangi (Balmer 
\& devaney, 2002). The number of IL-4 producing NKT cells, mainly CD4- NKT cells, was also increased at this time point, indicating that this early IL-4 production could polarize the immune response towards a Th2 profile. On the other hand, Koyama et al. observed that depletion of NK1.1-expressing cell has no effect on the Th2 response development during the gastrointestinal nematode Trichuris muris infection (Koyama, 2002).

\section{TREMATODE INFECTIONS}

W ith the exception of murine schistosomiasis, no study has been devoted to investigate the potential role of NKT cells during trematode infection. Schistosomiasis is a chronic parasitic disease caused by Schistosoma. In the case of $S$. mansoni, infection is initiated by trans-cutaneous penetration of cercariae. Following infection, parasites transform into schistosomula that reside in the skin for 3-7 days afterwards they migrate, through the bloodstream, to the lungs (1$2 \mathrm{wk}$ ) and then to the hepatic portal system, where the sexually differentiated male and female mate. A key feature of the immune response in $S$. mansoni-infected mice is the occurrence of a strong Th2 response triggered by parasite eggs that are gradually deposited in host tissues (i.e. the liver), as early as week 5 post-infection (Pearce \& macDonald, 2002). The mechanisms leading to the promotion of this Th2 dominated response are still obscure. We and others showed that glycoconjugates from egg Ags play crucial role in the Th2 response. This led us to hypothesize that egg glycolipids, through a CD1ddependent mode of $\mathrm{Ag}$ presentation, could be important in this setting (Faveeuw et al., 2002; Okano et al., 1999). In agreement with this postulate, we found that CD1d-deficient $\left(^{-/}\right)$BALB/c mice mounted a reduced Th2 response after the egg laying and developed a less marked fibrotic pathology, compared to wild type mice (Faveeuw et al., 2002). This observation was recently confirmed in $S$. mansoni-infected $\mathrm{C} 57 \mathrm{Bl} / 6$ mice (Mallevaey et al., 2007), indicating that the genetic background does not appear to influence the regulatory impact of NKT functions on the global immune response in this model. Thus, our results suggested a possible role of CD1d-restricted T cells in the early immunological events leading to the generation of Th2 response associated to the egg-induced pathology. In accordance with this assumption, Zaccone et al. reported that the treatment of autoimmune prone non-obese diabetic mice with schistosome eggs induced a protective Th2 response, an effect associated with an apparent expansion of NKT cells in the liver (Zaccone et al., 2003). This prompted us to investigate whether NKT cells could be activated during the course of infection. Flow cytometry analysis demonstrated that hepatic iNKT cells, as well as splenic iNKT and non-iNKT cells, become activated and expand during infection as early as 3-4 week post-infection (Mallevaey et al., 2007; Mallevaey et al., 2006), a time that just precedes with the full maturation of adult worms and the egg laying. More importantly, we observed that, upon schistosome egg encounter in the liver, hepatic iNKT cells produce both IFN- $\gamma$ and IL- 4 (Mallevaey et al., 2006). Thus, schistosome eggs, and possibly adult worms, might activate NKT cells in vivo, probably indirectly via APCs. Using bone marrow-derived DCs, we demonstrated that egg-sensitized WT, but not CD1d $\mathrm{d}^{-/}$DCs activate iNKT cells in vitro to produce IFN$\gamma$ and IL-4 whereas schistosomulum- or adult worm-sensitized DCs failed to do so (Mallevaey et al., 2007; Mallevaey et al., 2006). On the other hand, whatever the stage utilized, parasite-sensitized DCs failed to promote the activation of non-iNKT cells in vitro (Mallevaey et al., 2007) suggesting that in vivo, it might require other APC types. Schistosome eggs thus appear to be the only parasitic stage capable of activating, in a TCR-dependent manner, iNKT cells, although the mechanisms still remain unresolved. Albeit many attempts, and with the detection limit of our assay, we indeed failed to isolate eggderived activating lipids able to stimulate iNKT cells. Similarly, TLR (as well as IL-12) expression by DCs appear to be dispensable for in vitro iNKT cell activation, indicating that other pattern recognition receptors might be involved (Mallevaey et al., 2006). To study the potential role of iNKT and non-iNKT cells in the immune response during infection, $\mathrm{CD}_{1} \mathrm{~d}^{-/}$(which lack both iNKT and noniNKT cells) and Jo18 ${ }^{-/}$(which lack only iNKT cells) mice were used (Mallevaey et al., 2007). Our data indicate that NKT cells do not play a role in susceptibility/resistance of mice infected with S. mansoni. Moreover, neither iNKT cells nor non-iNKT cells are required to control the immune response early after infection ( 1 and 4 week post-infection). During the acute (week 7) and more chronic (week 12) stages of the disease, and relative to wild type animals, $\mathrm{CD}_{1} \mathrm{~d}^{-/}$mice developed a markedly reduced Th2 response, but maintained their ability to promote Th1 response. In marked contrast, J $\alpha 18^{-/-}$mice mounted a dramatically decreased Th1 cytokine response, a phenomenon associated with a more pronounced fibrotic pathology (Mallevaey et al., 2007). Thus, although these findings necessitate further confirmation (i.e. by mean of cell transfer), iNKT and non-iNKT cells seem to exert distinct, and perhaps complementary, functions on the Th1/ Th2 balance of the immune response during murine schistosomiasis; iNKT cells providing help for Th1 cell differentiation and non-iNKT cells for Th2 cell differentiation.

\section{CONCLUSIONS}

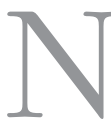
KT cells represent potent immunoregulatory cells and are attractive targets for immunotherapy. Although the literature is very limited, it 
seems (at least for murine schistosomiasis) that NKT cells could intervene in the development/control of immune responses and pathology during helminthiasis. More-thorough investigation is clearly necessary to better define their mode of activation and their regulatory functions. Moreover, information in humans is scarce and studies aiming at understanding the role of these cells should be encouraged. This may lead to better understand the biology of this fascinating immune cell population during chronic pathologies and to discover new immunomodulatory molecules.

\section{ACKNOWLEDGEMENTS}

T This work was supported by the Institut National de la Santé et de la Recherche Médicale, Université de Lille 2, and l'Institut Pasteur de Lille. We also thank "Agence Nationale de la Recherche" (program "Microbiologie, infections et Immunités", grant APV05103ESA) for supporting the NKTschisto project.

\section{REFERENCES}

Ambrosino E., Terabe M., Halder R.C., Peng J., Takaku S., Miyake S., Yamamura T., Kumar V. \& Berzofsky J.A. CrossRegulation between Type I and Type II NKT cells in regulating tumor immunity: a new immunoregulatory axis. J. Immunol., 2007, 179, 5126-5136.

BAlmer P. \& Devaney E. NKT cells are a source of early interleukin-4 following infection with third-stage larvae of the filarial nematode Brugia pahangi. Infect. Immun., 2002, 70, 2215-2219.

Bendelac A., Savage P.B. \& Teyton L. The biology of NKT cells. Annu. Rev. Immunol., 2007, 25, 297-336.

Brigl M., Bry L., Kent S.C., Gumperz J.E. \& Brenner M.B. Mechanism of CD1d-restricted natural killer T cell activation during microbial infection. Nat. Immunol., 2003, 4, 1230-1237.

Crowe N.Y., Coquet J.M., Berzins S.P., Kyparissoudis K., Keating R., Pellicci D.G., Hayakawa Y., Godfrey D.I. \& Smyth M.J. Differential antitumor immunity mediated by NKT cell subsets in vivo. J. Exp. Med., 2005, 202, 1279-1288.

Duthie M.S., Kahn M., White M., Kapur R.P. \& Kahn S.J. Critical proinflammatory and anti-inflammatory functions of different subsets of CD1d-restricted natural killer T cells during Trypanosoma cruzi infection. Infect. Immun., 2005, 73, 181-192.

Faveeuw C., Angeli V., Fontaine J., Maliszewsiki C., Capron A., Van Kaer L., Moser M., Capron M. \& Trottein F. Antigen presentation by CD1d contributes to the amplification of Th2 responses to Schistosoma mansoni glycoconjugates in mice. J. Immunol., 2002, 169, 906-912.

Fuss I.J., Heller F., Boirivant M., Leon F., Yoshida M., Fichtner-Feigl S., Yang Z., Exley M., Kitani A., Blumberg R.S., MANNon P. \& STROBER W. Nonclassical CD1d-restric- ted NK T cells that produce IL-13 characterize an atypical Th2 response in ulcerative colitis. J. Clin. Invest., 2004, 113, 1490-1497.

Godfrey D.I., MacDonald H.R., Kronenberg M., Smyth M.J. \& VAN KAER L. NKT cells: what's in a name? Nat. Rev. Immunol., 2004a, 4, 231-237.

Godfrey D.I. \& Kronenberg M. Going both ways: immune regulation via CD1d-dependent NKT cells. J. Clin. Invest., 2004b, 114, 1379-1388.

Halder R.C., Aguilera C., Maricic I. \& Kumar V. Type II NKT cell-mediated anergy induction in type I NKT cells prevents inflammatory liver disease. J. Clin. Invest., 2007, 117, 23022312.

Koyama K. NK1.1 ${ }^{+}$cell depletion in vivo fails to prevent protection against infection with the murine nematode parasite Trichuris muris. Parasite Immunol., 2002, 24, 527-533.

Kronenberg M. Toward an understanding of NKT cell biology: progress and paradoxes. Annu. Rev. Immunol., 2005, 23, 877-900.

Mallevaey T., Zanetta J.P., Faveeuw C., Fontaine J., Maes E., Platt F., Capron M., De-Moraes M.L. \& Trottein F. Activation of invariant NKT cells by the helminth parasite Schistosoma mansoni. J. Immunol., 2006, 176, 2476-2485.

Mallevaey T., Fontaine J., Breuilh L., Paget C., Castro-Keller A., Vendeville C., Capron M., Leite-de-Moraes M., Trottein F. \& FAveEuw C. Invariant and non-invariant Natural Killer T cells exert opposite regulatory functions on the immune response during murine schistosomiasis. Infect. Immun., 2007, 75, 2171-2180.

Mattner J., Debord K.L., Ismail N., Goff R.D., Cantu C. 3rd, Zhou D., Saint-Mezard P., Wang V., GaO Y., Yin N., Hoebe K., Schneewind O., Walker D., Beutler B., Teyton L., Savage P.B. \& Bendelac A. Exogenous and endogenous glycolipid antigens activate NKT cells during microbial infections. Nature, 2005, 434, 525-529.

Michel M.L., Keller A.C., Paget C., Fujio M., Trottein F., Savage P.B., Wong C.H., Schneider E., Dy M. \& Leite-DeMoRAEs M.C. Identification of an IL-17-producing NK1.1 (neg) iNKT cell population involved in airway neutrophilia. J. Exp. Med., 2007, 204, 995-1001.

NAGARAJAN N.A. \& KRONENBERG M. Invariant NKT cells amplify the innate immune response to lipopolysaccharide. J. Immunol., 2007, 178, 2706-2713.

Okano M., Satoskar A.R., Nishizaki K., Abe M. \& Harn D.A. Jr. Induction of Th2 responses and IgE is largely due to carbohydrates functioning as adjuvants on Schistosoma mansoni egg antigens. J. Immunol., 1999, 163, 6712-6717.

Paget C., Mallevaey T., Speak A.O., Torres D., Fontaine J., Sheehan K.C., Capron M., RyfFel B., Faveeuw C., Leite-DeMoraes M., Platt F. \& Trottein F. Activation of invariant NKT cells by toll-like receptor 9-stimulated dendritic cells requires Type I interferon and charged glycosphingolipids. Immunity, 2007, 27, 597-609.

Pearce E.J. \& MacDonald A.S. The immunobiology of schistosomiasis. Nat. Rev. Immunol., 2002, 2, 499-511.

Porcelli S.A. \& Moduin R.L. The CD1 system: antigen-presenting molecules for $\mathrm{T}$ cell recognition of lipids and glycolipids. Annu. Rev. Immunol., 1999, 17, 297-329. 
Tupin E., Kinjo Y. \& Kronenberg M. The unique role of natural killer T cells in the response to microorganisms. Nat. Rev. Microbiol., 2007, 5, 405-417.

Willcox B.E., Willcox C.R., Dover L.G. \& Besra G. Structures and functions of microbial lipid antigens presented by CD1. Curr. Trop. Microbiol. Immunol., 2007, 314, 73-110.

Zaccone P., Fehervari Z., Jones F.M., Sidobre S., Kronenberg M., DunNe D.W. \& CoOKE A. Schistosoma mansoni antigens modulate the activity of the innate immune response and prevent onset of type 1 diabetes. Eur. J. Immunol., 2003, 33, 1439-1449. 